\title{
Increasing Hemagglutination Inhibition Antibodies against Two Lineages of Type B Influenza Virus in 2017-2018 Winter Season in Beijing, China
}

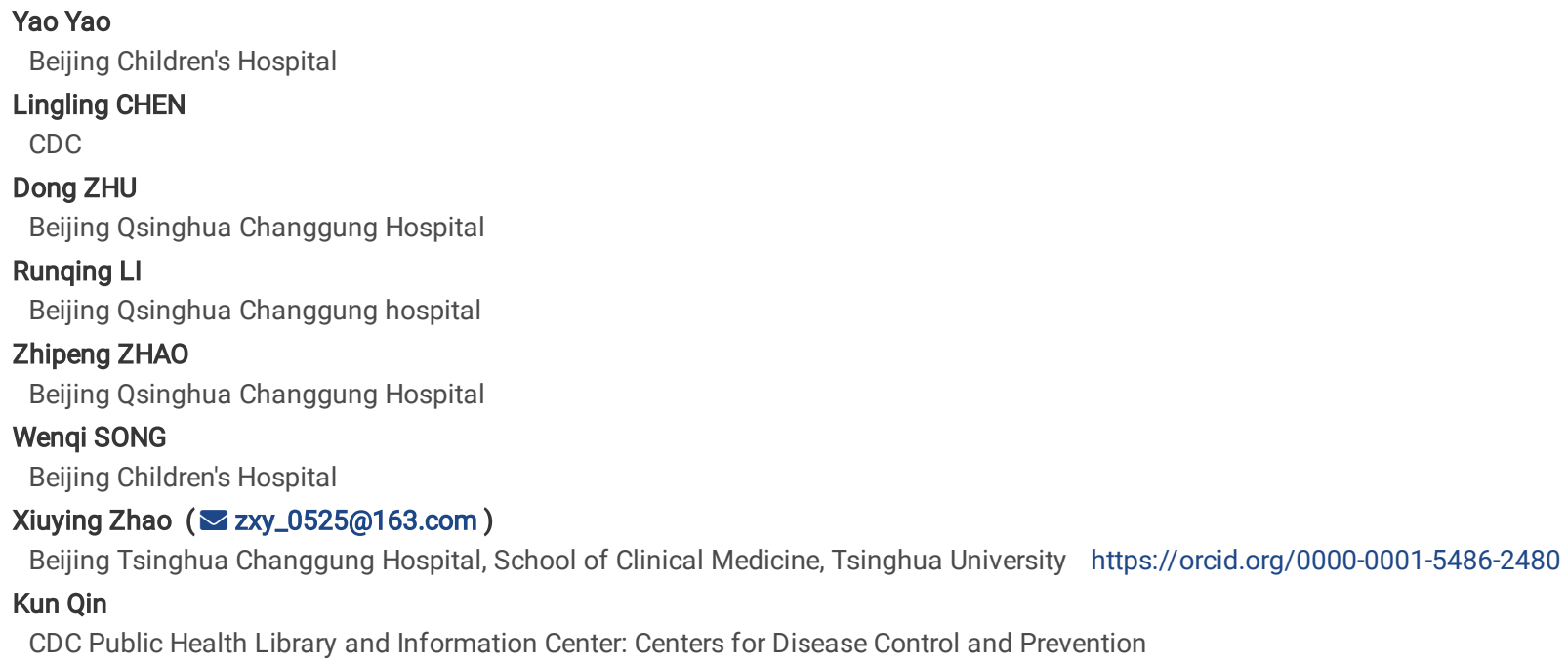




\section{Abstract}

Influenza virus circulates every year with lower activity than that of influenza A virus in China. During 2017 to 2018 winter season, a sharp surge of influenza activity dominated by type B/Yamagata lineage virus caused unprecedented medical burden in Beijing. The research aimed to understand the underlying mechanism for this circulation and be prepared for epidemics in the future. Sera samples collected from the patients in 2016-2017 and 2017-2018 flu seasons were tested for profiling hemagglutinin inhibition $(\mathrm{HI})$ antibodies against both prevailing Victoria and Yamagata lineages of type $\mathrm{B}$ influenza viruses. It showed that the seroprevalence against both lineages of the virus in 2017-2018 winter was higher than that in 2016-2017, while no difference of the seroprevalence was observed between the two viruses. Meanwhile, significant elevated geometric mean titer (GMT) against both lineages of influenza B viruses was found in the specimens collected during 2017-2018 flu season than that from 2016-2017, suggesting the viruses might undergo antigenic changes. These results also suggested that lower GMT against both type B variants in 2016-2017 might serve as an immunological niche for the dominating of B/Yamagata virus in China during 2017-2018 winter season. Our findings have implication that there was a significantly elevation of HI antibodies to influenza viruses B in 20172018, compared in 2016-2017. On the other hand, the low level of $\mathrm{HI}$ antibodies to both B/Y and B/V in 2016-2017 could contribute to the severe B/Y epidemic in 2017-2018 to some extent.

\section{Introduction}

Since October 2017, information from the World Health Organization (WHO) has highlighted the increasing level of influenza activity compared with previous flu seasons (WHO. 2018). It dramatically reached the peak and caused a huge medical burden in Beijing and such situation had been lasting till April, 2018 (Kochanek et al. 2018). Sharply increasing number of patients with influenza-like-illness (ILI) suggested that the circulating virus might have evaded the herd immunity or mutated to achieve a higher transmissibility (Bedford et al. 2015). This predication soon was confirmed by the evidence from China CDC that Yamagata lineage of type B influenza virus (Flu B) was the predominant strain resulting the epidemic, although few cases were reported to be type A influenza virus (Flu A) infection including pdmH1N1/2009 and H3N2 (CDC. 2018).

Flu B virus firstly identified in 1940 was associated with considerable hospital admissions and deaths worldwide annually (FRANCIS. 1940; Chen and Holmes. 2008). During early 1980 s, it evolved into two lineages, designated as $B / Y a m a g a t a(B / Y)$ and $B /$ Victoria (B/V), showing distinct antigenicity and transmission pattern (Chen R et al. 2008; Kanegae et al. 1990; Vijaykrishna et al. 2015). Since then, Flu B viruses have co-circulated with Flu A virus during epidemic season and the dominant lineage has changed over years in different geographical locations (Ye et al. 2018; Yang et al. 2018). Several studies have pointed out the differences of the epidemiology between B/Y and B/V lineages, such as younger average ages of persons preferred being attacked by and higher transmissibility of B/V viruses, compared with B/Y viruses (Vijaykrishna et al. 2015; Caini et al. 2019; Yoshihara et al. 2019).

For a long time, much effort has been done on Flu A virus, whereas Flu B virus was relatively less investigated, resulting in poor lineage matches with recommended influenza vaccine strains and the control options require further improvement (Htwe et al. 2019; Noh et al. 2018). HI tests measure the presence of specific antibodies of IgG in sera that inhibit virus-mediated agglutination of erythrocytes (Rowe et al. 1999). This is a sensitive assay that is affected, in some level, by nonspecific hemagglutinin inhibitors in the sera. However, it is a particularly reliable method for influenza surveillance, providing confirmative result for suspect individuals with successive sera samples, also profile the herd immunity against upcoming influenza variant, in which case tiers $\geq 1: 40$ are considered protective (Skevaki et al. 2012). In the present study, serological assay against two lineages of Flu B viruses circulating in China was determined to investigate the cross-sectional $\mathrm{HI}$ antibodies in defined samples. Our findings provided insights on low level herd immunity to influenza B virus prior to the B/Y lineages epidemic would in some level contribute to this epidemic.

\section{Materials And Methods Sera samples and ethics approval}

Two batches of serum samples from Beijing Tsinghua Changgung Hospital (BTCH) and Beijing Children Hospital (BCH), respectively, were used in the present study. Batch one was 190 sera samples collected during Nov, 2016 to Apr, 2017 (2016-2017) from outpatients in BTCH with the age ranging from 0.5 to 94 years old. Batch two was 283 sera samples collected from outpatients presenting acute respiratory infections (ARI) from BCH during the Dec, 2017 to Mar, 2018 (2017-2018), with the age ranging from 0.5 to 17 years old. Samples in Batch one was subdivided into 3 groups according to ages and diagnosis, group 1 from 69 adults aged from 18 to 94 years old and excluded respiratory diseases, group 2 from 75 patients aged from 0.5 to 17 years old present other than respiratory symptoms, group 3 from 46 patients aged from 0.5 to 17 years old and presenting ARI. All sera samples were remaining from routine clinical tests and were stored at $-40{ }^{\circ} \mathrm{C}$ till use. The studies did not involve any health-related patient information and were approved by the Ethics Committee of both Beijing Children's Hospital and Beijing Tsinghua Changgung Hospital (Approval No. 2018-k-130 / 17120-0-01).

\section{Representative influenza viruses for $\mathrm{HI}$ assay}

Type B influenza viruses isolated from China during the two winter seasons were selected for $\mathrm{HI}$ assay on the basis of data collected by the World Health Organization (WHO) as well as our own study (Zhu et al. 2019). For Victoria lineage, B/Jiangxi_yushui/11102/2014 which was phylogenetically and antigenically close to the recommended vaccine strainB/Brisbane/60/2008, belonging to V1A sublineage, was selected as the antigen for HI. For Yamagata lineages, the representative virus B/Beijing/BTCH_71/2018, belonging to Y3 sublineage isolated in early 2018 in Beijing was used (Zhu et al. 2019). The phylogenetic relationship of the selected viruses was presented (Fig. 1). Viruses were amplified in 9-11-day-old specific pathogen free (SPF) chicken embryonated eggs at $35^{\circ} \mathrm{C}$ for 2 days. The allantoic fluid were collected and cleared by low-speed centrifugation. The titer of the virus was determined by $\mathrm{HA}$ assay and viral antigen aliquots was stored at $-80^{\circ} \mathrm{C}$ till use. All experiments associated with live viruses were performed in the biosafety level 2 plus laboratory. 
Figure 1. Phylogenetic tree of the HA gene of type B influenza viruses used in the study.

Phylogenic tree was constructed using the partial HA genes (370-610NT covering the most important positions distinguishing the Victoria and Yamagata lineages) from the clinic isolates and full-length HA sequences from the GenBank as well as GISAID. Strains labeled with black triangle represented as B/Victoria and B/Yamagata lineage viruses were used as antigens in the present study.

\section{Hemagglutinationinhibition $(\mathrm{HI})$ assay}

Serum samples were examined for the presence of antibodies against the hemagglutinin of the selected type B influenza viruses by $\mathrm{HI}$ assay as described previously (Bodewes et al. 2011; Wang et al. 2012). Briefly, serum samples were heat inactivated at $56^{\circ} \mathrm{C}$ for 1 hour and then were absorbed by $20 \%$ ( $/ \mathrm{W}$ ) turkey red blood cell (TRBC) to reduce the non-specific binding. 2-fold serial dilutions with 1:10 staring dilution of pretreated serum samples were subsequently incubated with 8 hemagglutination units of influenza virus or phosphate-buffered saline (PBS) for 30 min at $37^{\circ} \mathrm{C}$, and subsequently, $1 \%$ TRBC was added. HI pattern were read after incubation for $30 \mathrm{~min}$ at $22^{\circ} \mathrm{C}$. The highest dilution of serum that still gave complete inhibition of the hemagglutination was recorded as the titer. Serum samples were considered negative when they failed completely to inhibit agglutination of TRBC by any of the selected viruses. Serum samples collected from mice before and after immunization with each of the type B influenza viruses were used as negative and positive controls, respectively. Considering previous exposures to Flu B viruses or vaccinations in individual's life would have interference on $\mathrm{HI}$ antibody profile, we took $\geq 1: 80$ as cut-off limit for "positive reaction" of recently infection.

\section{Statistics}

Data analyses were performed using SPSS software (version 17.0; SPSS Inc., Chicago, IL, USA). Nonparametric test was used for comparing the age difference of children and GMT of the sera samples. Correlation of HI titers against two lineages of Flu B virus was employed Spearman tests. The Pearson Chi-square test or Fisher's exact tests were performed to evaluate $\mathrm{HI}$ antibodies seroprevalence to Yamagata and Victoria lineages of Flu B virus, with cut-off value as $\mathrm{HI}$ titers $\geq 1: 80$. Two-sided at the $5 \%$ level of significance was considered statistically remarkable in all tests.

\section{Results}

\section{HI titers against two lineages of Flu B viruses in sera from 2016-2017}

The $\mathrm{HI}$ titers to the two lineages of Flu B viruses in sera from 2016-2017 were compared. Result indicated that the frequency with $\mathrm{HI}$ titers over the cut-off value in the 3 subgroups did not show difference, either to $B / Y$, or to $B / V$ lineage virus (Table 1). HI titers in group 3, the sera from children present $A R I$ did not increase as compared to the group 2, sera from children without ARI $(P=0.47$ for $\mathrm{B} / \mathrm{Y}$ and $P=0.78$ for $\mathrm{B} / \mathrm{V})$. Hence, we put group 2 and group 3 together ( $\mathrm{n}=$ $121)$ to represent $\mathrm{HI}$ value in children (CHI) from 2016-2017. The $\mathrm{HI}$ titers in $\mathrm{CHI}$ group were also compared to subgroup 1 of adults and no difference was found $(P=0.65$ for $\mathrm{B} / \mathrm{Y}$ and $P=0.49$ for $\mathrm{B} / \mathrm{V})$. The results indicated a lower epidemic of Flu $\mathrm{B}$ in 2016-2017 winter, with the $\mathrm{HI}$ titers in children and adult showing no difference previous the $B / Y$ epidemic year.

Table 1

Summary and comparing of $\mathrm{HI}$ titers to B/Y and B/V lineages in 2016-2017

\begin{tabular}{|lllllll|}
\hline Sera cohorts & $\begin{array}{l}\text { Group1(N=69) } \\
\text { No. (\%) }\end{array}$ & $\begin{array}{l}\text { Group2 }(\mathrm{N}=75) \\
\text { No. }(\%)\end{array}$ & $\begin{array}{l}\text { Group3 }(\mathrm{N}=46) \\
\text { No. }(\%)\end{array}$ & $\begin{array}{l}P \text { value } \\
\text { (3 groups) }\end{array}$ & $\begin{array}{l}P \text { value } \\
\text { (group 2 to 3) }\end{array}$ & $\begin{array}{l}P \text { value } \\
\left.\text { (CHI to adults }^{\dagger}\right)\end{array}$ \\
\hline B/Yamagata & $14(20.29)$ & $19(25.33)$ & $9(19.57)$ & 0.69 & 0.47 & 0.65 \\
\hline B/Victoria§ & $13(18.84)$ & $18(24.00)$ & $10(21.74)$ & 0.76 & 0.78 & 0.49 \\
\hline$P$ value & 1.00 & 1.00 & 1.00 & $/$ & $/$ & $/$ \\
\hline
\end{tabular}

The percentages were estimated as a fraction of total cases belonging to each category. $P$ values were estimated using $\chi^{2}$ tests or Fisher's exact tests (between $B / Y$ and $B / V$ of each group).

${ }^{\dagger}$. CHI: summary of group 2 and group 3 to represent samples from children. Adults: samples from adult in group 1

‡. B/Beijing/BTCH_71/2018 was used as antigen representative of B/Yamagata lineage virus.

§.B/Jiangxi_Yushui/11102/2014 was used as antigen representative of B/Victoria lineage virus

\section{Comparing HI titers against two lineage of Flu B viruses in 2016-2017 and 2017-2018}

HI titer against prevailing Flu B viruses was compared using sera samples from 2016-2017 and 2017-2018. All the samples from children aged 0.5-17 years and no difference being found $(P=0.77)$. There were 28 sera samples in $2016-2017 \mathrm{CHI}(\mathrm{n}=121)$ groups being found as $\mathrm{HI}$ positive against both lineages of Flu $B$ viruses, with the frequency at $23.14 \%$, and no difference being found between $B / Y$ and $B / \mathrm{V}$ lineage. However, there were $66.08 \%$ showed $\mathrm{HI}$ positive against $B / Y$ lineage and $59.72 \%$ showed $H I$ positive against $B / V$ lineage in the $2017-2018$, with no significant difference was observed to $B / Y$ and $B / V$ lineages in this season, though the $\mathrm{HI}$ positivity to $\mathrm{B} / \mathrm{Y}$ lineage did mildly increase than $\mathrm{B} / \mathrm{V}(66.08 \%$ vs $59.72 \%, P=0.054)$. It was significantly increased as the $\mathrm{HI}$ titers in 2017-2018 than in 2016-2017, either to B/Yamagata $(P<0.01)$ and B/Victoria $(P<0.01)$, indicating that $\mathrm{HI}$ antibody in children increased 
simultaneously, to both $\mathrm{B} / \mathrm{Y}$ and $\mathrm{B} / \mathrm{V}$ viruses with the spreading of $\mathrm{B} / \mathrm{Y}$ lineage (Table 2). On the other hand, a moderate correlation was found between $\mathrm{HI}$ titers to $\mathrm{B} / \mathrm{V}$ and $\mathrm{B} / \mathrm{Y}$ in 2016-2017 ( $r=0.58)$ and 2017-2018 ( $r=0.49)$ (Fig. 2).

Table 2

Comparing prevalence of $\mathrm{HI}$ titers to $\mathrm{B} / \mathrm{V}$ and $\mathrm{B} / \mathrm{Y}$ lineages in 2016-2017 and 2017-2018

\begin{tabular}{|llll|}
\hline Sera cohort/Antigen & $\begin{array}{l}\text { 2016-2017(N=121) } \\
\text { No. (\%) }\end{array}$ & $\begin{array}{l}\text { 2017-2018(N = 283) } \\
\text { No. (\%) }\end{array}$ & $p$ value \\
\hline B/Yamagata $^{\dagger}$ & $28(23.14 \%)$ & $187(66.08 \%)$ & $<0.01$ \\
\hline B/Victoria $^{\ddagger}$ & $28(23.14 \%)$ & $169(59.72 \%)$ & $<0.01$ \\
\hline Pvalue & 1.00 & 0.054 & $/$ \\
\hline
\end{tabular}

The percentages were estimated as a fraction of total cases belonging to each category. P values were estimated using $\chi^{2}$ tests or Fisher's exact tests (age groups), and $\mathrm{p}$ values of 0.05 or less are shown in bold.

${ }^{\dagger}$. B/Beijing/BTCH_71/2018 was used as the representative of B/Yamagata lineage virus.

${ }^{\ddagger}$.B/Jiangxi_Yushui/11102/2014 was used as the representative of B/Victoria lineage virus

Figure 2. Comparison of HI titer distributions against two lineages of Flu B viruses by Spearman tests.

We can see categories of $\mathrm{HI}$ titer to both lineages increased significantly in 2017-2018 than in 2016-2017. Moderate correlation can be found between $\mathrm{B} / \mathrm{Y}$ and $\mathrm{B} / \mathrm{V}$ lineage as the $\mathrm{HI}$ titers in 2016-2017 (a) and 2017-2018 (b).

\section{Antigenic drift of Flu B viruses from 2016-2017 to the 2017-2018}

Geometric mean titer (GMT) was usually used for evaluating the influenza vaccine efficacy and potency in defined population. In the study, the GMT of HI titer against both lineages of Flu B viruses in sera collected in 2017-2018 (74.16 against B/Y and 67.57 against B/V, respectively) was much higher than that collected in 2016-2017 (31.87 against B/Y and 26.44 against B/V, respectively). Significant increase in the GMT to both lineages could be seen in 20172018, as compared to 2016-2017. However, we did not find difference as the GMT to $\mathrm{B} / \mathrm{Y}$ and $\mathrm{B} / \mathrm{V}$ either in $2016-2017(P=0.14)$, or in 2017-2018 ( $P=0.11)$. Given the same antigens used in the $\mathrm{HI}$ assay for sera samples from two different years, we predict that Flu $B$ viruses might undergo antigenic drift and it is the reason for the B/Y lineage virus evades herd immunity. Collectively, these data suggested weak HI response in 2016-2017 to both Flu B viruses may contribute to the severe epidemic of Flu B in winter of 2017 (Table 3), and the antigenic drift produce a transition and higher HI titers against most recent/homologues infection.

Table 3

GMT of HI titers against two lineages of Flu B viruses in sera from children in 2016-2017 and 2017-2018.

\begin{tabular}{|c|c|c|c|c|c|}
\hline & Sera cohorts & $\begin{array}{l}\text { B/Yamagata }{ }^{\dagger} \\
\left(95 \% \mathrm{Cl}^{\S}\right)\end{array}$ & $\begin{array}{l}\text { B/Victoria }{ }^{\ddagger} \\
\left(95 \% \mathrm{Cl}^{\S}\right)\end{array}$ & $P$ value & \\
\hline & $\begin{array}{l}2016-2017 \\
(N=121)\end{array}$ & $31.87(27.56-36.86)$ & $26.44(21.54-32.46)$ & 0.14 & \\
\hline & $\begin{array}{l}2017-2018 \\
(N=283)\end{array}$ & $74.16(66.39-82.83)$ & $67.57(60.51-75.44)$ & 0.11 & \\
\hline & $P$ value & $<0.01$ & $<0.01$ & & \\
\hline \multicolumn{6}{|c|}{ GMT was calculated based on the $\mathrm{HI}$ titer. P values were estimated using nonparametric tests and $\mathrm{p}$ values of 0.05 or less are shown in bold. } \\
\hline \multicolumn{6}{|c|}{${ }^{\dagger}$. B/Beijing/BTCH_71/2018 used as the representative of B/Yamagata lineage virus. } \\
\hline \multicolumn{6}{|c|}{ ‡. B/Jiangxi_Yushui/11102/2014 used as the representative of B/Victoria lineage virus. } \\
\hline §. Cl, Confidence interval. & & & & & \\
\hline
\end{tabular}

\section{Discussion}

The $\mathrm{HI}$ assay serves as a golden method for serologic diagnosis of influenza, if suitable viral antigen was employed. In the context that an abrupt spread of influenza $\mathrm{B} / \mathrm{Y}$ lineage virus, we performed this $\mathrm{HI}$ antibody screening study using cryopreserved sera samples, aiming to evaluate the $\mathrm{HI}$ antibody transition after the outbreak of B/Y lineage. Setting 1:80 as cut-off value, we compared the positivity of HI titer and GMT to both B/Y and B/V lineages in $2017-2018$ to previous year of 2016-2017. Result indicated that the positivity of HI titer in 2017-2018 was significantly higher than that in 2016-2017, and the GMT was 
also significantly increased in 2017-2018 than the previous year. However, we did not find any difference as the HI titers to B/Y and B/V in the two consecutive years. In 2016-2017, positivity and GMT of HI titer to both B/Y and B/V were at a low level. Significantly, in 2017-2018, positivity and GMT of HI titers to $B / Y$ and $B / V$ increased simultaneously, though many reports indicated that $B / Y$ was the leading reason for severe spreading of influenza during the time (Dayan. 2018). The $\mathrm{HI}$ antibody to $\mathrm{B} / \mathrm{Y}$ lineage with percentage of $66.1 \%$ exceeds reported positivity of antigen tests to Flu B at around $10-20 \%$, and reported positivity of RT-PCR assay to Flu B at 38\% in ILI cases during 2017-2018 winter, suggesting recessive infection would be a primary reason for acquiring the $\mathrm{HI}$ antibodies under Flu B epidemic.

Sudden surge of Flu B/Y virus during the 2017-2018 winter may reflect changes of the viral fitness (Virk et al. 2019), as well as herd immunity against this leading strain. The prevailing $B / Y$ variant become to dominate might reflect the vaccine effectiveness (VE) or natural situation cannot provide adequate protective immunity against this strain. In this study, low GMT of HI to both B/Y and B/V in previous epidemic year (2016-2017) add value to this assumption and reinforce the emergence of the $B / Y$ epidemic. $H$ titer could not only serve as an indicator for the protective immunity after the immunization, but also hint infection/transmission status in a well-defined population (Bodewes et al. 2011). Flu B had been detected at very low incidence in ILI patients during 20182019 seasonal flu epidemic (unpublished data by our group), which could be attributed to previous year's development of HI antibodies to B/Y and B/V lineages.

In China, general public has gradually developed a strong "vaccine hesitancy". People including high risk individuals are reluctant or refuse to be vaccinated despite the availability of influenza vaccine due to a variety of reasons. Influenza vaccination coverage rate in China was at $1.5 \%$ of the total population between 2004 and 2014 (Yang et al. 2016). It can be postulated that establishment of herd immunity against influenza virus mainly relies on the natural infection. Low immunization coverage and lack of B/Y antigen in current trivalent influenza vaccine (TIV) in China (before 2018-2019 flu season) may provide favorable conditions for the dominance and prevalence of B/Y virus. Long-term co-circulating viruses of Flu A H1/H3 subtype accompanied by decreased $\mathrm{HI}$ antibody to both Flu B virus may serve as an immunological niche for the B/Y lineage virus spreading in China during the 2017-2018 winter. Our findings have implications that quadrivalent influenza vaccines (QIV) should be timely updated for better prevention against seasonal influenza epidemics.

It has been well documented that antisera raised against Victoria lineage of Flu B virus shared low cross reaction with that against Yamagata lineage (Rota et al. 1992). However, distinct immunodominance of the two lineages of Flu B virus may affect or elicit more potent cross reactive or protective antibodies based on previous history of infection needs more in-depth investigations. Such scenario has been illustrated by pdm/H1N1/2009 virus which replaced previous seasonal H1N1 strain and established in human population apt to induce cross protection antibody response (Victoraet al. 2015; Andrews et al. 2015). Under such background, $\mathrm{HI}$ assay could be used as evaluation of infection and herd immunity but not suitable for diagnosis in clinical context as cross reaction between $B / Y$ and $B / V$ lineages from previous infection could not be excluded.

In summary, our study indicates that there was a significantly elevation of HI antibodies to influenza viruses B in children with ARI in 2017-2018, compared with children in 2016-2017. On the other hand, the low level of $\mathrm{HI}$ antibodies to both B/Y and B/V in 2016-2017 could contribute to the severe B/Y epidemic in 2017-2018 to some extent. Limitations exist in the study. First of all, we used preserved clinical samples from children with ARI to perform the crosssectional study, the sera were not so typical and previous infection or vaccination might affect production of HI titers. Secondly, the sera samples preserved in 2016-2017 were not sufficient enough, we had to make a composition using samples from children with or without ARI together, after excluding difference between the two groups, and to compare to those from 2017-2018. Lastly, since we did not perform HI assay to Flu A, we are not sure the influence of Flu A to the $\mathrm{HI}$ reaction of Flu $\mathrm{B}$.

\section{Abbreviations}

\section{HI}

Hemagglutinin inhibition

\section{GMT}

Geometric mean titer

WHO

World Health Organization

ILI

Influenza-like-illness

Flu B

Type B influenza virus

Flu A

Type A influenza virus

$\mathrm{B} / \mathrm{Y}$

B/Yamagata

B/V

B/Victoria

BTCH

Beijing Tsinghua Changgung Hospital

$\mathrm{BCH}$

Beijing Children Hospital

ARI

Acute respiratory infections 


\section{SPF}

Specific pathogen free

TRBC

Turkey red blood cell

PBS

Phosphate-buffered saline

CHI

$\mathrm{HI}$ value in children

VE

Vaccine effectiveness

TIV

Trivalent influenza vaccine

QIV

Quadrivalent influenza vaccines

\section{Declarations}

Ethics approval and consent to participate

Not applicable. This article does not contain any studies with human participants performed by any of the authors, so the consent to participate is not applicable.

Consent for publication

Not applicable.

Competing interests

The authors have no conflicts of interest to declare.

Availability of data and materials

All relevant data are within the manuscript.

Funding

This work was supported by a grant from Beijing Municipal Science \& Technology Commission Program of China (grant no. Z181100001718148).

Contributions

ZHAO Xiuying and QIN Kun conceived and designed research. Yao Yao and CHEN Lingling conducted experiments. SONG Wenqi , Zhao Zhipeng and LI Runqing helped to conduct experiments. QIN Kun and CHEN Lingling analyzed data. Zhao Xiuying and QIN Kun wrote the paper. All authors read and approved the final manuscript.

Corresponding author

Correspondence to Dr. Xiuying Zhao and Dr. Kun Qin.

\section{References}

Andrews SF, Huang Y, Kaur K, Popova LI, Ho IY, Pauli NT (2015) Immune history profoundly affects broadly protective B cell responses to influenza. Science translational medicine 7(316):192. 10.1126/scitranslmed.aad0522. 0, ). doi

Bedford T, Riley S, Barr IG, Broor S, Chadha M, Cox NJ (2015) Global circulation patterns of seasonal influenza viruses vary with antigenic drift. Nature 523(7559):217-220. https://doi:10.1038/nature14460. 0

Bodewes R, de Mutsert G, van der Klis FRM, Ventresca M, Wilks S, Smith DJ (2011) Prevalence of antibodies against seasonal influenza A and B viruses in children in Netherlands. Clinical vaccine immunology: CVI, 18(3), 469-476. https://doi:10.1128/CVI.00396-10

Caini S, Kusznierz G, Garate VV, Wangchuk S, Thapa B, de Paula Júnior FJ (2019) The epidemiological signature of influenza B virus and its B/Victoria and B/Yamagata lineages in the 21st century. http://europepmc.org/articles/PMC6742362?pdf=render. Accessed 2019.

https://doi.org/10.1371/journal.pone.0222381

CDC C (2018) China flu Weekly Report http://ivdc.chinacdc.cn/cnic/zyzx/lgzb/201801/t20180114_158170.htm. Accessed January 14 2018

Chen R, Holmes EC (2008) The Evolutionary Dynamics of Human Influenza B Virus. J Mol Evol 66(6):655. https:// doi:10.1007/s00239-008-9119-z 0 
Dayan, Wang (2018) The epidemic situation in China (2018 version). https://mp.weixin.qq.com/s?

_biz=MzAxNzEwNjY2MA==\&mid=2650984676\&idx=1\&sn=93eef7006b86c8f70d12fe5c3e9dd260\&chksm=801ce36fb76b6a799fecde4cfb240f2fb2806dda9e Accessed January 282018

FRANCIS T (1940) A NEW TYPE OF VIRUS FROM EPIDEMIC INFLUENZA. Science 92:405-408 0

Htwe KTZ, Dapat C, Shobugawa Y, Odagiri T, Hibino A, Kondo H (2019) Phylogeographic analysis of human influenza A and B viruses in Myanmar, 20102015. PloS one 14(1):e0210550-e0210550. https:// doi:10.1371/journal.pone.0210550 0

Kanegae Y, Sugita S, Endo A, Ishida M, Senya S, Osako K (1990) Evolutionary pattern of the hemagglutinin gene of influenza B viruses isolated in Japan: cocirculating lineages in the same epidemic season. Journal of virology 64(6):2860-2865 0

Kochanek M, Böll B, Shimabukuro-Vornhagen A, Welte T, Wieland U, Pletz M (2018) Influenza season 2017/2018 - business as usual? Der Internist 59(10):1122-1124. https://doi:10.1007/s00108-018-0501-7. 0

Noh JY, Choi WS, Song JY, Lee HS, Lim S, Lee J (2018) Significant circulation of influenza B viruses mismatching the recommended vaccine-lineage in South Korea, 2007-2014. Vaccine 36(35):5304-5308. https://doi:https://doi.org/10.1016/j.vaccine.2018.07.021. 0

WHO (2018). Influenza update - 306. https://www.who.int/influenza/surveillance_monitoring/updates/2018_01_08_update_GIP_surveillance/en/. Accessed January 082018

Rota PA, Hemphill ML, Whistler T, Regnery HL, Kendal AP (1992) Antigenic and genetic characterization of the haemagglutinins of recent cocirculating strains of influenza B virus. J Gen Virol 73(Pt 10):2737-2742. https://doi:10.1099/0022-1317-73-10-2737. 0

Rowe T, Abernathy RA, Hu-Primmer J, Thompson WW, Lu X, Lim W (1999) Detection of antibody to avian influenza A (H5N1) virus in human serum by using a combination of serologic assays. J Clin Microbiol 37(4):937-943 0

Skevaki CL, Papadopoulos NG, Tsakris A, Johnston SL (2012) Microbiologic Diagnosis of Respiratory Illness: Practical Applications. In: Wilmott RW, Boat TF, Bush A, Chernick V, Deterding RR, Ratjen F Kendig \& Chernick's Disorders of the Respiratory Tract in Children (Eighth Edition). W.B. Saunders, Philadelphia, pp. 399-423. https://doi.org/10.1016/B978-1-4377-1984-0.00024-3. 0. In (Eds

Victora GD, Wilson PC (2015) Germinal center selection and the antibody response to influenza. Cell 163(3):545-548. https://doi:10.1016/j.cell.2015.10.004. 0

Vijaykrishna D, Holmes EC, Joseph U, Fourment M, Su YCF, Halpin R (2015) The contrasting phylodynamics of human influenza B viruses. eLife 4:e05055e05055. https://doi:10.7554/eLife.05055. 0

Virk RK, Jayakumar J, Mendenhall IH, Moorthy M, Lam P, Linster M (2019) Divergent evolutionary trajectories of influenza B viruses underlie their contemporaneous epidemic activity. Proceedings of the National Academy of Sciences

Wang TT, Parides MK, Palese P (2012) Seroevidence for H5N1 influenza infections in humans: meta-analysis. Science (New York, N.Y.), 335(6075), 14631463. https://doi:10.1126/science. 1218888

Yang J, Atkins KE, Feng L, Pang M, Zheng Y, Liu X (2016) Seasonal influenza vaccination in China: Landscape of diverse regional reimbursement policy, and budget impact analysis. Vaccine 34(47):5724-5735. https://doi.org/10.1016/j.vaccine.2016.10.013. 0

Yang J, Lau YC, Wu P, Feng L, Wang X, Chen T (2018) Variation in Influenza B Virus Epidemiology by Lineage, China. Emerg Infect Dis 24(8):1536-1540. https://doi:10.3201/eid2408.180063. 0

Ye F, Chen XJ, Guan Wd, Pan SH, Yang ZF, Chen RC (2018) Analysis of influenza B virus lineages and the HA1 domain of its hemagglutinin gene in Guangzhou, southern China, during 2016. Virol J 15(1):175-175. https://doi:10.1186/s12985-018-1085-5. 0

Yoshihara K, Le MN, Toizumi M, Nguyen HA, Vo HM, Odagiri T (2019) Influenza B associated paediatric acute respiratory infection hospitalization in central vietnam. Influenza Other Respir Viruses 13(3):248-261. https://doi:10.1111/irv.12626. 0

Zhu Dong, Lok C, Chao S, Chen L, Li R, Zhao Z, Dong J, Qin K, Zhao xiuying (2019) Detection and characterization of type B influenza virus from influenza-like illness cases during the 2017-2018 winter influenza season in Beijing, China. Archives of virology. https://doi:10.1007/s00705-019-04160-w

\section{Figures}




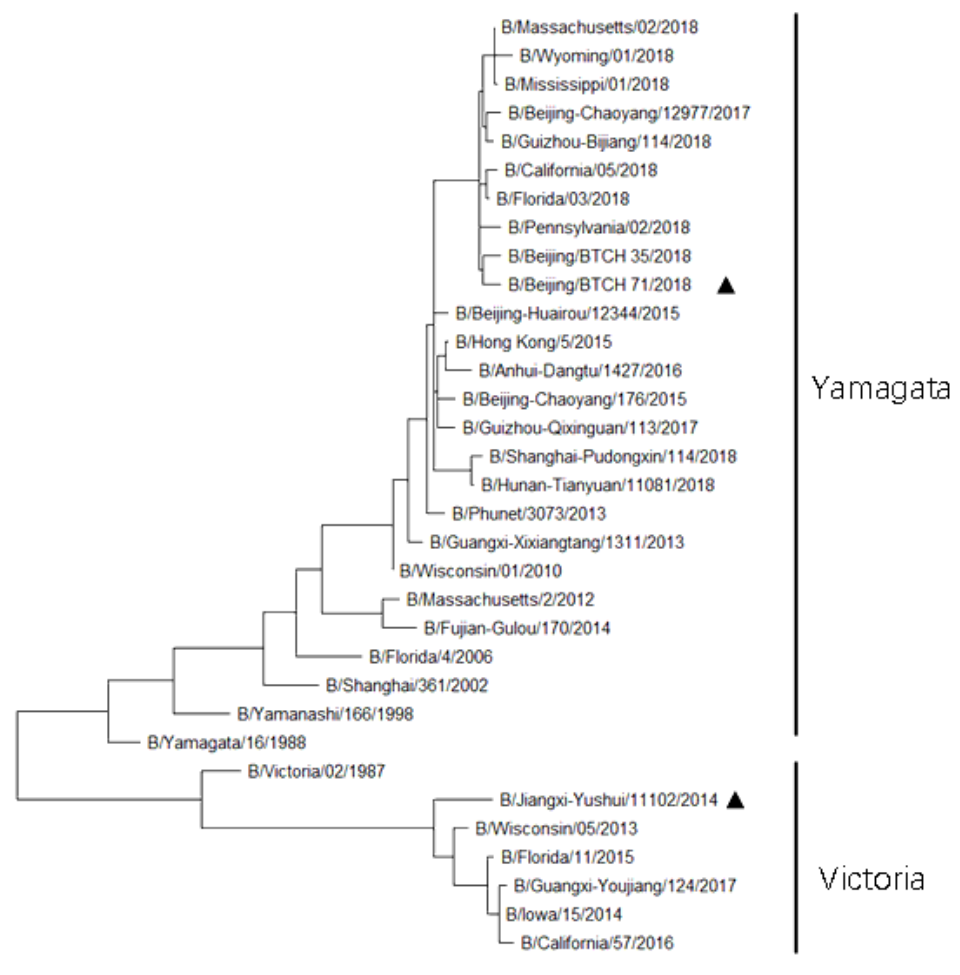

0.020

Figure 1

Phylogenetic tree of the HA gene of type B influenza viruses used in the study. Phylogenic tree was constructed using the partial HA genes (370-610NT covering the most important positions distinguishing the Victoria and Yamagata lineages) from the clinic isolates and full-length HA sequences from the GenBank as well as GISAID. Strains labeled with black triangle represented as B/Victoria and B/Yamagata lineage viruses were used as antigens in the present study.
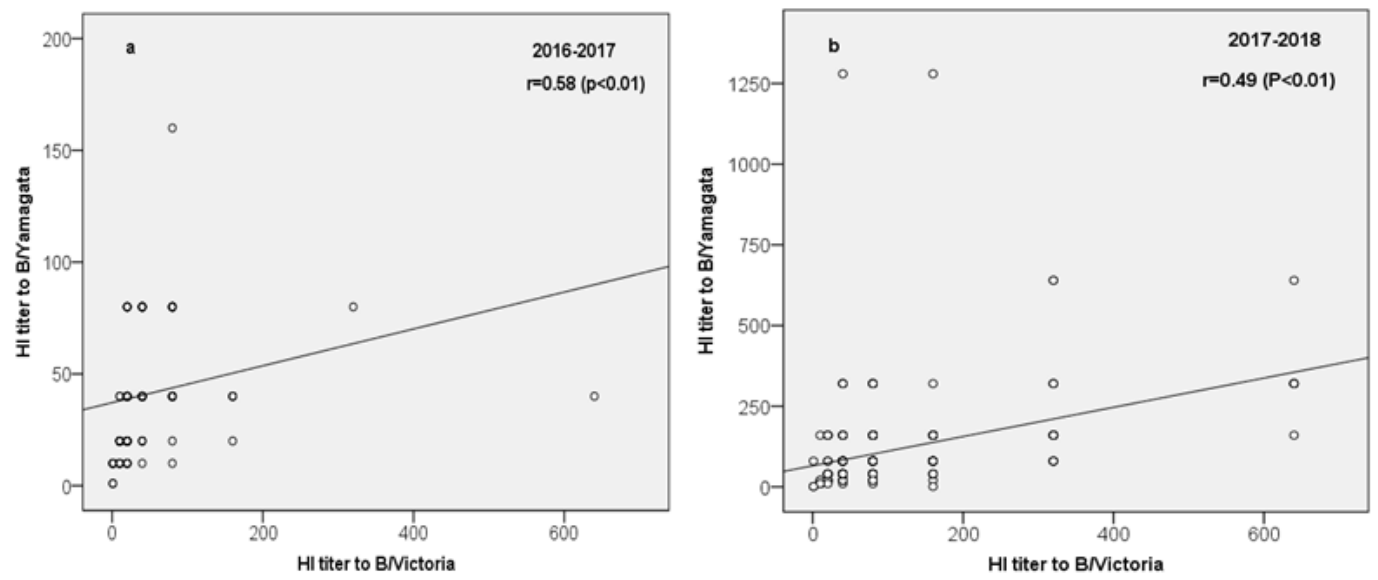

Figure 2

Comparison of $\mathrm{HI}$ titer distributions against two lineages of Flu B viruses by Spearman tests. We can see categories of $\mathrm{HI}$ titer to both lineages increased significantly in 2017-2018 than in 2016-2017. Moderate correlation can be found between B/Y and B/V lineage as the HI titers in 2016-2017 (a) and 20172018 (b). 